\title{
Critical Analysis of the User Interfaces for the Disabled Community
}

\author{
Kunal Gupta \\ Singhania University \\ Pacheri Beri, Distt. Jhunjhunu, \\ Rajasthan, India
}

\author{
Usman Ali Khan \\ King Abdul Aziz University \\ Jeddah, \\ Kingdom of Saudi Arabia
}

\begin{abstract}
Human Computer Interaction has always always been oriented towards providing ease of access to the users of the systems. Much work has been done on this area for nondisable person which formulates the largest segment of the commercial population. A lot of effort is required to be made to make technology accessible to the disabled community. The paper discuss several problems associated with individuals with disabilities. Software systems are designed all over the world for disabled, but they lack the luster through which the disable may be motivated to make optimal usage of the technology. Our research provides for the design of an abstract model which can be considered as the baseline foundation on which frameworks for developing Adaptive Intelligent User Interfaces for Disabled may be developed. Such interfaces will not only capture the interest of the disabled individuals but also provide a socio-economic reform, through which the participation of the disabled might be increased, and the use of their intellect may be given a positive direction for the betterment of the Society.
\end{abstract}

\section{General Terms}

Human Computer Interaction, User Interfaces.

\section{Keywords}

User Interfaces for Disabled Individuals, Life Cycle Models for User Interfaces, Adaptive User Interfaces, Adaptibility Framework, Assisted Cognitive Learning.

\section{INTRODUCTION}

Computers, Internet, Mobile Phones, and the large Communications Network of which it is a part, have radically changed the lives of billions. We use the technology in almost all aspects of our lives. The Information technology had made a deep and positive impact on all the sections of the societies. Well, almost all ! There has been one section of the Society who have not gain benefit from the technology in the ways it should have - "The Disabled Community". Technology, especially Information Technology has the power to change the lives of the disabled community for the better, to reduce the difference between disabled and non disabled individuals[1] .

Most of the Software Engineering Companies do not develop programs for special users because they do not see fantasy in this poor market. Most of the Computer Systems in the Market are designed for non-disabled users[2]. But, more than 600 million people (that is above $10 \%$ of the total population) in the world are disabled as a consequence of mental, physical or sensory impairment[3]. They are entitled to the same rights as all other human beings and to equal opportunities. Too often their lives are handicapped by physical and social barriers in society which hamper their full participation.
Because of this, millions of children and adults in all parts of the world often face a life that is segregated and debased. It is imperative, that Software Solution be designed for the Disabled Community, which can empower them, turning disability into a national asset. The people with Disability will eventually be able to act as an engine to social and ethical changes in society.

In our Paper, we have studied the Problems associated with Disable Community in India, and have further explore the work done so far for the disabled community. We then critically analyze and identified, the User Interfaces for the Disabled to be the backbone of the software developed for the Community, and evaluated what the success factors of such an interface should be.

\section{PRESENT STATE OF THE DISABLE COMMUNITY IN INDIA - A CASE STUDY}

Having a disability places you in the world's largest minority group. As the population ages this figure is expected to increase. Eighty per cent of persons with disabilities live in developing countries, according to the UN Development Program (UNDP). The World Bank estimates that 20 per cent of the world's poorest people have some kind of disability, and tend to be regarded in their own communities as the most disadvantaged [4].

In India itself, some 40 to 80 million persons are with disability. But low literacy, few jobs and widespread social stigma are making disabled people among the most excluded in India. Children with disabilities are less likely to be in school, disabled adults are more likely to be unemployed, and families with a disabled member are often worse off than average. With better education and more access to jobs, people with disabilities can become an integral part of society, as well as help generate higher economic growth that will benefit the country as a whole[5].

In the years to come, the number of disabled people in India is expected to rise sharply as age related disabilities grow and traffic accidents increase. This is borne out by the fact that internationally, the highest reported disability rates are in OECD countries.

Several kinds of Problems are associated with People with Disabilities in India:

a. Socio-Economic Profile of Persons with Disabilities: A Large numbers of children remain out of school in India, a majority of them being disabled. They are less likely to be in the school by a factor of 4 to 5 times SC/ST children. If anyhow, they happen to be admitted in school, they rarely progress beyond primary levels. This eventually 
leads to lower levels of employments as well as incomes for the Disabled class.

b. Attitudes: The Disabled faces negative attitudes all around them, even from their families, and often the disabled themselves hold this negative attitude for themselves, deterring disabled persons from taking an active part in the family, community or workforce. Those suffering from mental illness or mental retardation face the worst stigma and are subject to severe social exclusion.

c. Education: While the Sarva Shiksha Abhiyan (SSA)has made a concerted effort to promote the inclusion of children with special needs, the system faces challenges in identifying these children and responding to their needs. Only around $1 \%$ of funds under SSA are spent on inclusive education. And, the budget for educating children with mild to moderate disabilities in regular school settings has not increased commensurately since the focus on inclusive education began in the 1970s.

d. Employment: Even though many disabled adults are capable of productive work, disabled adults have far lower employment rates than the general population. In fact, employment of people with disability actually fell from $43 \%$ in 1991 to $38 \%$ in 2002 , despite the country's economic growth. In the public sector, despite a $3 \%$ reservation since 2003 , only $10 \%$ of posts have been identified as "suitable". The quota policy is also covers just three types of disability - locomotors, hearing and visual. The situation is far worse in the private sector. The sector has few incentives for hiring disabled people.

e. Social Protection: Though centrally sponsored antipoverty programs have reservations for people with disabilities, the numbers who have benefited are well below the minimum laid down. The new National Rural Employment Guarantee Act has dropped reservations for the disabled entirely, though some states (e.g. AP) are making efforts to include disabled people. Few people with disabilities are aware of such programs and many states lack focus on social protection for PWD.

f. Policies and Institutions: Despite having one of the most progressive policy frameworks for persons with disabilities, India falls short in implementation. The Persons with Disabilities Act of 1995 is the cornerstone of India's policy framework, but its enforcement faces many challenges. For one, the Ministry of Social Justice and Empowerment - the nodal agency for disability- is perennially short of resources. There is therefore a need to strengthen public-private partnerships with NGOs. However, there are concerns about weak monitoring mechanisms and accountability of public funds. And, persons with disability need to be treated more like active participants than clients. There is thus an urgent need for reforms at all levels.

g. Access: Physical accessibility in buildings, transportation and the like, as well as access to services is key for persons with disability. Guidelines already exist for buildings that are friendly for both the disabled and the elderly. But these guidelines need to be adopted into building bye-laws to make them legally binding.

\section{PROVIDING FOR CONSTRUCTIVE CHANGE FOR THE DISABLED COMMUNITY}

If we refer history, we can see a great number of people who have contributed significantly to society. It is a great achievement for any man to perform extraordinary acts - but it is even more so when this is done despite a terrible disability. Vincent Van Gogh (Disability: Mental Illness) was a Dutch Painter and is regarded as one of the greatest painters the world has ever seen. His paintings have immensely contributed to the foundations of modern art. Ludwig van Beethoven (Disability: Deaf) is widely regarded as one of the greatest composers in history. Christy Brown was an Irish author, painter and poet who had severe cerebral palsy. Doctors considered him to be intellectually disabled as well. He is most famous for his autobiography My Left Foot, which was later made into an Academy Award-winning film of the same name. Stephen William Hawking is a British theoretical physicist, whose world-renowned scientific career spans over 40 years. His books and public appearances have made him an academic celebrity and he is an Honorary Fellow of the Royal Society of Arts, a lifetime member of the Pontifical Academy of Sciences, and in 2009 was awarded the Presidential Medal of Freedom, the highest civilian award in the United States. Stephen Hawking is severely disabled by motor neuron disease, likely a variant of the disease known as amyotrophic lateral sclerosis (or ALS). It would be an understatement to say that high level of intellect exists in the Disabled Community, how you harness it is another matter of fact.

The Information Technology Revolution has changed the human condition in fundamental ways. These changes have the potential to reduce the difference between disabled and non-disabled individuals. The disabled depends on the technology to aid their senses and magnify and transform the effects of their movements. Neither the Blind, nor the quadriplegic, can access information and participate in the transformation of the same without the help of information technology. The difference between the individuals with disabilities and those without becomes simply a matter of the participation with the Technology. The individual with Disabilities may turn their Disabilities in National Assets, if they can actively participate in the various processes assisted via Information Technology. And in turn, this participation can be enhanced via the use of appropriate User Interfaces, providing the human touch, to the relevant Software.

In the past, efforts have been made to design rich user interfaces[6],[7],[8],[9],[10], to provide an easy and effective access to the disabled users, enhancing Usability of the Software. Usability has been defined by [11] as follows: "The extent to which a product can be used by a specified set of users, to achieve specified goals (tasks) with effectiveness, efficiency, and satisfaction in a specified context of use". Several researchers have produced sets of generic usability principles, which can be used in improving software[12],[13],[14]. Unfortunately, the definitions of such design and usability principles are mostly too broad or general, and, in some cases, very vague. It has been shown repeatedly that general usability advice is not effective on its own when designing systems for an environment that can assist a disabled individual to access Software. Therefore, it is generally difficult for a non-usability expert or a novice to apply these principles in a particular domain and situation, taking into account the unique factors that give rise to 


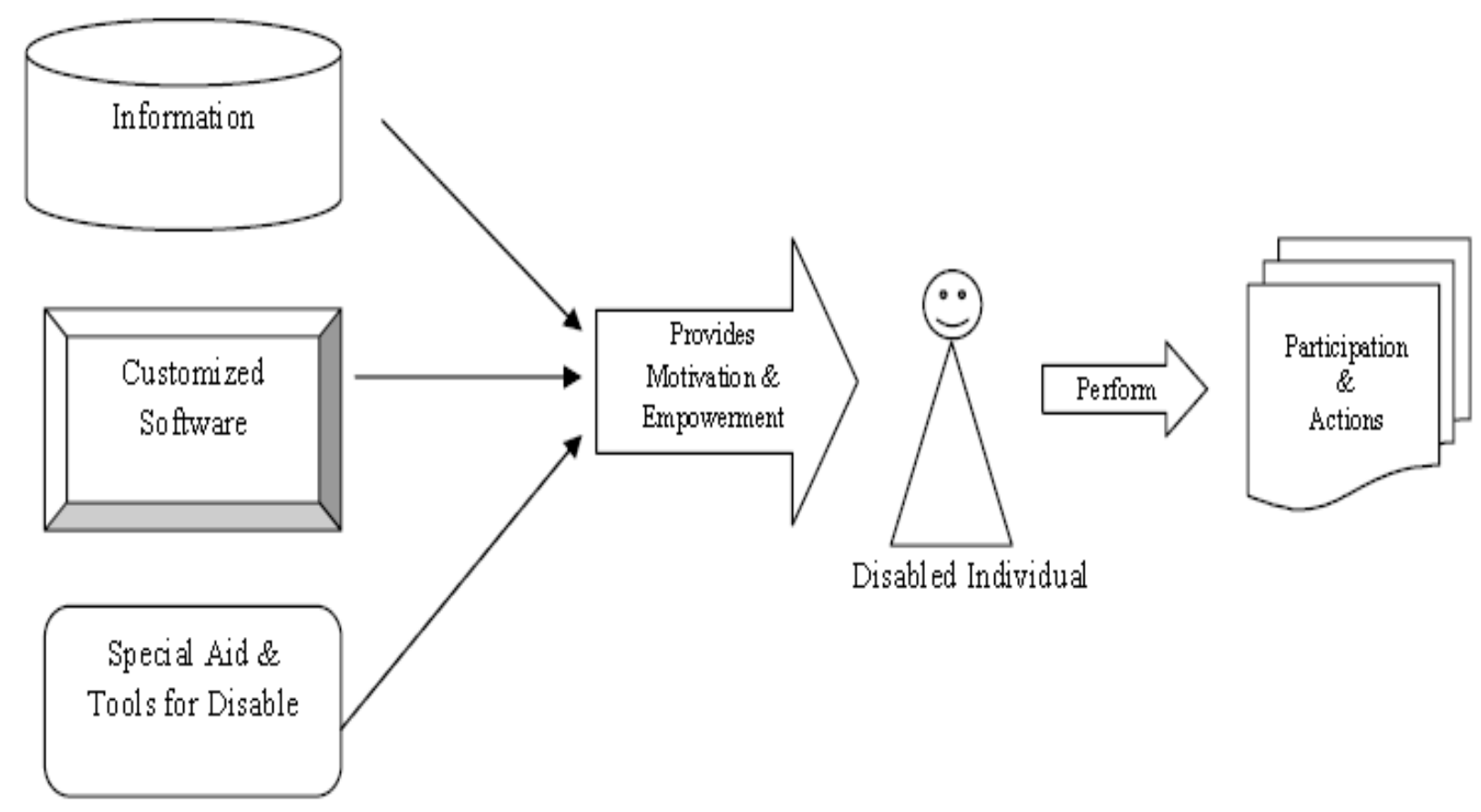

Fig 1: Information, Customized Softwares, Special Aids \& Tools for Disabled can Provide Motivation \& Empowerment to a Disable Person to actively Participate in Processes \& take actions in Socio-Economic Reforms.

\section{RELATED WORK: LIFE CYCLE MODELS FOR USER INTERFACES}

Initially, in order to design User Interfaces for non-disabled person, standard engineering approaches were used. Although functionally complete user interfaces may be built and even generated from eg. object models, they will not be very useful until the context of the software was identified. Eventually, the practitioners and proponents of the Human Computer sought out for specialized models for Software Design. [15] have produced a model of development to rectify some of the problems in the "classic" life cycle model of SE. In this approach, HCI principles and interface design drive the whole process. Other such life cycle models include the Star model of [16], the Usability Engineering life cycle of [12], and the Interaction Design model of [17]. These methods also introduce various strategies for the development of effective user interfaces. The argument for putting forward these alternative development models was that by spotting user requirements early on in the development cycle, there will be less of a demand for code generation and modification in the later stages of systems development. But all of these models were oriented towards Software for non-disabled person. A model for designing an effective User Interfaces for disabled is vital for the creation of interest of the community for bringing a social-economic reform.

Problems in that domain. Work needs to be done which can motivate and empower a Disabled to perform actions necessary to improve their participation in the SocioEconomic Reform Process as displayed in Figure 1.

\section{AN ABSTRACT MODEL FOR THE SPECIAL NEED OF DISABLED PERSON}

Before we go on to present an abstract model which will provide us with the building block of a concrete foundation for building an efficient UI for Disabled, let us first consider the properties that a UI for disable should have. Some of the vital characteristics (but not limited to) that a UI for Disable should possess, are listed in Table1.

Table 1. Desirable characteristics of an efficient UI for Disable Person

\begin{tabular}{|l|l|}
\hline \multicolumn{1}{|c|}{ Property } & \multicolumn{1}{c|}{ Description } \\
\hline $\begin{array}{c}\text { Intelligent and } \\
\text { Adaptable }\end{array}$ & $\begin{array}{l}\text { A special need for intelligence and } \\
\text { adaptive criteria is sought. This is the } \\
\text { first and foremost important criteria } \\
\text { needed for development of an efficient } \\
\text { and effective User Interface for Disabled } \\
\text { Person. It is of utmost importance that } \\
\text { the interface should be able to analyze } \\
\text { the disabled user's interests and behavior } \\
\text { and should adapt according to their need. } \\
\text { Since the user cannot adopt according to } \\
\text { the user, we would like our interface to } \\
\text { adapt according to the needs of the } \\
\text { users. }\end{array}$ \\
\hline $\begin{array}{l}\text { Intention } \\
\text { Prediction }\end{array}$ & $\begin{array}{l}\text { The ability of the UI to recognize that a } \\
\text { user is willing to carry out a particular } \\
\text { action; it can configure itself accordingly } \\
\text { and provide help as and when necessary. }\end{array}$ \\
\hline $\begin{array}{l}\text { Profile } \\
\text { Management- }\end{array}$ & $\begin{array}{l}\text { Thermulation of Profile according to } \\
\text { individual's needs and preferences helps } \\
\text { the UI to store user preference } \\
\text { information and update it according to } \\
\text { user's action. The UI accordingly } \\
\text { updates the user's profile as difference }\end{array}$ \\
\hline
\end{tabular}




\begin{tabular}{|l|l|}
\hline $\begin{array}{l}\text { Interaction } \\
\text { Tracker }\end{array}$ & $\begin{array}{l}\text { By user's behavior are observed } \\
\text { interaction between the User Interface } \\
\text { and the user, we might be able to extract } \\
\text { much useful information, which might } \\
\text { give us an idea of user's needs }\end{array}$ \\
\hline $\begin{array}{l}\text { Behavior } \\
\text { Pattern Tracker }\end{array}$ & $\begin{array}{l}\text { The UI should be able to compose new } \\
\text { events from previously modeled events } \\
\text { and build or modify the transformation } \\
\text { functions of the modeled events }\end{array}$ \\
\hline Assistance & $\begin{array}{l}\text { Another important feature of such a UI } \\
\text { is that it should be able to provide } \\
\text { Assistance in Cognitive Learning } \\
\text { through an aid (i.e. external person). The } \\
\text { disability of a user can limit their } \\
\text { learning potential of the Software. } \\
\text { Accordingly, an aid can assist in the } \\
\text { Cognitive Learning Process to enhance } \\
\text { the learning process. }\end{array}$ \\
\hline
\end{tabular}

We further present an abstract model that can formulate the basis of efficient framework to be designed in future for effective and efficient UI for Disabled Community. Figure 2 represents the abstract model as the Special Need Abstract Model for User Interface for Disabled Individuals (SNAMUIDI).

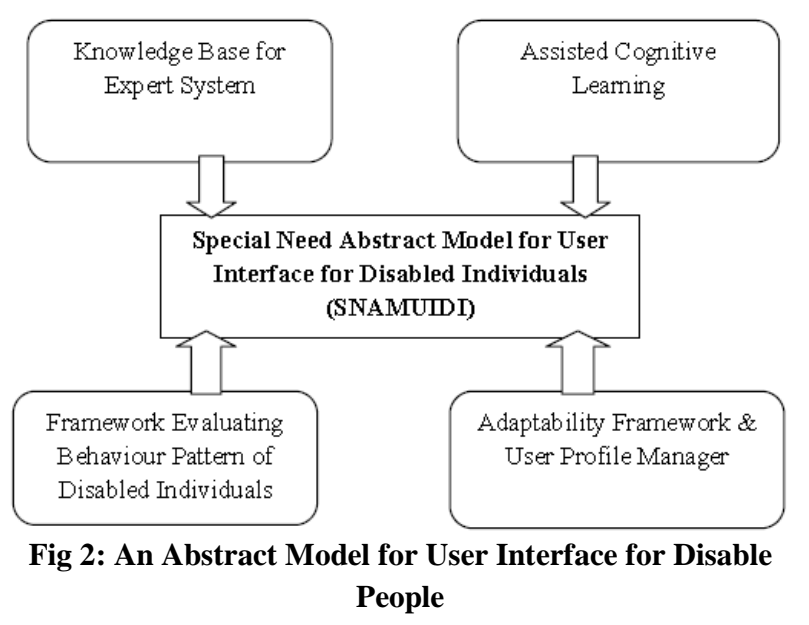

The Abstract Model displayed above will act as a baseline foundation for building User Interfaces for Disabled. More elements can be added in it to formulate a framework for building efficient and effective interfaces which can motivate disabled to participate effectively in the process and to contribute his intellect accordingly. The elements being displayed above are as follows. In the Core is the Abstract Model which takes inputs, processes information and interacts with the sub models surrounding it. The Knowledge Base for expert system will contain the rules, predicates and information from the knowledge base that has been carefully designed with reference to the various classifications of the disabilities of the people who will make use of the system accordingly. The Framework Evaluating Behavior Pattern of Disabled Individuals will keep a track of the behavior of Individual Users using the Interface, and analyze their habits, reactions and behavior, will provide help accordingly, and interact with the core model to make subsequent changes and to transfer information as and when necessary. The Adaptability Framework \& User Profile Manager will aid in the maintenance of User Profiles, making subsequent changes whenever the changes in habits and behavior of the user are observed by the model. The adaptability framework will change the Interface according to the needs of the user, since the user cannot adapt to the interface, the interface will have to adapt according to the needs of the user in order to assist as well as create interest in the interaction to achieve the maximum. The Assisted Cognitive Model will provide for Cognitive Learning to the disabled user via the means of an aid. It is essential that an aid (assistance) be provided to the disabled, as the learning curve of the user may not be good let alone optimal. An aid will not only provide an acquaintance to the interface but effectively provide an enhanced learning curve for the disabled user. It may certainly happen in several case where a known person be an aid to the disable. The person can provide a level of comfort to the disable, and provide them an eased up communication with the interface that would have not been possible otherwise. The core essentially communicates with these sub models and provide guidelines to them as and when necessary.

The abstract model above will promote automated learning and personalized adaptation of the User Interface. The threshold values will be adjusted dynamically according to the user's behavior pattern, which is stored in user's profile. The policies framing will be based on the frequency of user rejection or selection desirable for balancing short term and long term learning of the interface. The UI modeled in aid with above model will ensure the increased usability of the software, resulting in the enhanced level of user's participation, thus enabling the intellect of the disable user to be utilized in a productive manner which can subsequently contribute significantly to the society.

\section{CONCLUSION}

In this paper, we have brought forward the problems that are faced by the disabled community in general. It is noteworthy, that the disability of the disable community prevents them to be socially accepted as one of the society. Information Technology is bridging the gap between the disable and the non-disable. The disable can prove to be of great values to the society if Interfaces are provided which can enable the disable to participate in the process of social and economic reforms. Much work has been done on providing models for the Interfaces for non disabled as it is profitable. Little work has been done for non disabled. We provide an abstract model for the disable community which can empower the designers to design interfaces through which the disable can be motivated to contribute to the society, which in turn will uplift them morally, socially, economically and in ethical forms. Much work needs to be done here forth.

The subsequent paper and our future work will contain the architectural framework through which user interfaces can be designed that can illuminate interests in the mind of the disabled. We would then work on the Requirement Elicitation Process for such Interfaces, which can attribute to the successful design of efficient and effective Interfaces.

\section{REFERENCES}

[1] J. Perry, E. Macken, N. Scott, J. McKinley. "Disability, Inability and Cyberspace". From Battya Friedman "Designing Computers for People - Human Values and the Design of Computer Technology", Stanford: CSLI Publication, December, 1998.

[2] E.P. Glinert, and B.W. York. 1992. "Computers and people with disabilities". Comm. ACM 35, Pgs $32-35$. May 1992. 
[3] World Program of Action Concerning Disabled Person http://www.un.org/esa/socdev/ enable /diswpa01.htm

[4] Disabled World - Disability News for all the Family: http://www.disabled-world.com/ disability/statistics/\#ixzz11736Sjnc

[5] The World Bank http://www.worldbank.org.in/WBSITE/EXTERNAL/CO UNTRIES/

SOUTHASIAEXT/INDIAEXTN/0,,contentMDK:21557 057 pagePK:1497618 piPK:217854 theSitePK:295584, 00.html

[6] K. Moustakas, L. Dybkjaer, O. Aran, D. Tzovaras and N. O. Bernsen. "Using Modality Replacement to Facilitate Communication Between Blind and Hearing Impaired People." Multimedia, IEEE Volume 18 Issue 2, Pages 26- 37, Feb 2011

[7] F. Iacopetti, L. Fanucci, R. Roncella, D. Giusti, A. Scebba - "Game Console Controller Interface for People with Disability." Complex, Intelligent and Software Intensive Systems, 2008. Pages 757 -762, March 2008.

[8] C. E. Steriadis and P. Constantinou "Designing HumanComputer Interfaces for Quadriplegic People". ACM Transactions on Computer-Human Interaction, Vol. 10, No. 2, Pages 87-118, June 2003.

[9] A. Pereira, R.Arnaro, A. Lopes, J.B. Lopes, "Tictat- toe, An Agent to Support Game Playing by Severely Handicapped Persons (in Port. Jogo do Galo, Agente de Apoio Utiliza ao de Jogos pot Deficientes Profimdos)", submitted to the 10th Portuguese Computer Graphics Conference.
[10] P. Biswas. "Simulating HCI for Special Needs".SIG Access Newsletter, Issue 89, Sep 2007.

[11] ISO 9241-11 (1999). "Ergonomic requirements for office work with visual display terminals". Part 11 Guidance on usability. Retrieved from http:// w w w . i s o . o r g. / i s o/ en/cat a logue Detail Page.c at a logue

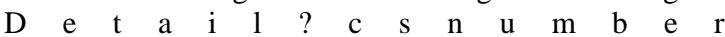
$=16883 \& \mathrm{icsi}=13 \& \mathrm{lcsz}=180 \& \mathrm{lc} 53=$

[12] D.J. Mayhew, "The usability engineering lifecycle: A practitioner's handbook for user interface design". San Francisco: Morgan Kaufmann, 1999.

[13] J. Preece, Y. Rogers, H.Sharp, D.Benyon, S.Holland, \& T. Carey. "Human-computer interaction". Harlow, UK: Addison-Wesley, 1994

[14] B. Shneiderman "Universal usability". Communication of the ACM, 43(5), Pgs 84-91, 2000.

[15] R. C. Williges, B.H. Williges, \& J. Elkerton. "Software interface design". In G. Salvendy (Ed.), Handbook of human factors (pp. 1414- 1449). New York: John Wiley \& Sons, 1987.

[16] H.R. Hartson, \& D. Hix. "Human-computer interface development: Concepts and systems for its management". ACM Computing Surveys, 21,Pgs: 592.1989 .

[17] M. Kaufmann. J.Preece, Y.Rogers, \& H.Sharp "Interaction design: Beyond human-computer interaction”. New York: John Wiley \& Sons, 2002. 